\title{
“Adiós querida mía, adiós tesoro". Las acciones comunicativas de los suicidas apasionados en Buenos Aires durante el último tercio del siglo XIX
}

"Goodbye my dear, goodbye treasure". The communicative actions of passionate suicides in Buenos Aires during the last third of the 19 th century.

Julián Arroyo

DOI: https://doi.org/10.24215/23468971e117

Centro de Estudios Sociales de América Latina-

CONICET - Universidad Nacional del Centro de la

Provincia de Buenos Aires, Argentina

julianarroyo86@gmail.com

Recepción: 28 Marzo 2020

Aprobación: 15 Junio 2020

\section{RESUMEN:}

En el presente trabajo abordamos, desde una perspectiva histórica y sociocultural, un conjunto de casos de suicidio ocurridos en la ciudad de Buenos Aires durante el último tercio del siglo XIX, con el fin de analizar las acciones comunicativas llevadas adelante en las narraciones asociadas con pasiones románticas, sentimientos amorosos y conflictos conyugales. En este sentido, nos proponemos mostrar que si bien hubo acciones que buscaban generar dolor y pesar, también había otras que estaban orientadas a preservar la memoria del suicida entre los otros significativos.

Palabras Clave: Suicidio, Muerte, Amor, Buenos Aires.

\section{Abstract:}

In this paper we analyze suicide cases that occurred in the city of Buenos Aires during the last third of the nineteenth century. From a historical and sociocultural perspective, we study communicative actions in stories associated with romantic passions, love feelings and marital conflicts. Our goal is to show that there were actions with the intention of generating pain and sorrow, and there were also other acts to preserve the memory of suicide among their significant others.

KEYWORDS: Suicide, Death, Love, Buenos Aires.

El presente trabajo tiene por finalidad llevar adelante una contribución al conocimiento de las representaciones de la muerte y, en particular, del suicidio desde una perspectiva histórica y sociocultural. ${ }^{1}$ Para ello, analizamos un conjunto de casos ocurridos en la ciudad de Buenos Aires durante el último tercio del siglo XIX. ${ }^{2}$ En este período se difundieron nuevas ideas sobre los actos suicidas, sobre todo, al interior del ámbito científico y académico porteño. Mientras los asentamientos urbanos crecían aceleradamente, aparecieron una serie de problemas que las distintas ramas de la ciencia positivista trataron de explicar y prevenir, como las enfermedades, el delito, la propagación de los vicios y los comportamientos inmorales (como el juego o la prostitución), las patologías mentales o las muertes por mano propia. En este marco, como han mostrado trabajos anteriores (Otero, 1991, 2004), los suicidios fueron descubiertos en la ciudad de Buenos Aires como fenómeno social, cuyo aumento acelerado en la población despertaba preocupación. Una de las formas de representar el crecimiento de la tasa de suicidios era la de una epidemia contagiosa, una suicidio-manía, producida por las transformaciones de la vida moderna y civilizada. El higienismo, la psiquiatría alienista, la medicina legal y la criminología, desde diferentes ángulos, se ocuparon de estudiar los suicidios en Buenos Aires.

Dada la atención prestada por los contemporáneos a los sucesos de este tipo en la capital del estado argentino, optamos por estudiar estos casos y cómo fueron representados por los actores sociales de la época. 
Estos fueron relevados a partir de la consulta de sumarios judiciales del fondo "Tribunal Criminal" de la ciudad de Buenos Aires, disponibles en el Archivo General de la Nación [en adelante, AGN, FTC]. ${ }^{3}$ Estos abarcan el período que va de 1860 a 1888. Para llevar adelante nuestra investigación relevamos 722 expedientes, en los que figuran un total de 724 casos de suicidio (500 consumados y 224 tentativas). Asimismo, también hemos consultado algunos ejemplares de los diarios "La Prensa" y "La Nación", a fin de observar los discursos que circulaban en los medios gráficos acerca de los casos de suicidio.

En los diferentes expedientes descubrimos distintos modos de representar al suicida. Había relatos en los que este era un individuo desesperado por conflictos familiares o por problemas materiales; en otros, se trataba de sujetos que tenían sus "facultades mentales alteradas" por diversos tipos de enfermedades mentales. En el presente trabajo, nos centraremos en las narraciones protagonizadas por suicidas apasionados, es decir, aquellas historias en las que estaban de por medio sentimientos amorosos y conflictos conyugales. ${ }^{4}$

$\mathrm{Al}$ observar estos relatos, en primer lugar, identificamos una mayor proporción de hombres y mujeres de menos de 20 años (27,38\%); en el conjunto de los casos, esta franja etaria representó un porcentaje menor, 13,67\%. Al mismo tiempo, la proporción de personas mayores de 40 años que se quitaron la vida por amor $(5,95 \%)$ es menor que en el total (18,09\%). También cabe destacar que los quinquenios de " 16 a 20 " y " 21 a 25 " tuvieron valores superiores a los de la generalidad de los casos analizados. Además, los quinquenios de “31 a 35" y "36 a 40" presentaron porcentajes (4,76\%, en el primero, y 5,95\%, en el segundo) que son equivalentes a la mitad de los valores de esos subgrupos etarios en el total de las narraciones consultadas (10,5\% y $11,05 \%$, respectivamente). Por otro lado, si observamos los valores al clasificar de acuerdo con el género a los que se suicidaron por cuestiones amorosas, también encontramos variaciones. Si estos últimos fueron en un $48,81 \%$ varones y un $51,19 \%$ mujeres, la representación de cada uno de los sexos en el total era más asimétrica $(78,18 \%$ y $21,82 \%$, respectivamente). Esta diferencia se acentúa más si comparamos a los hombres y mujeres de menos de 20 años. Los sujetos de sexo femenino en dicha franja etaria (6,77\% de los 724 suicidios relevados) representaban el $20 \%$ de los 84 casos de suicidio por causas determinantes asociadas con el amor y los conflictos de pareja. En los varones, en cambio, los porcentajes casi no variaron: mientras en el total eran el 6,91\%, en los suicidios por cuestiones amorosas representaban el 7,14\%. Desde nuestra perspectiva, estos datos están vinculados con los distintos horizontes de expectativas que tenían los hombres y mujeres de acuerdo a la etapa de la vida que transitaran. Es probable que para las mujeres de entre 15 y 25 años, la esperanza de encontrar pareja y casarse fuera mayor que en años posteriores; en general, se consideraba que se quedarían para "vestir santos" si no lo conseguían antes de los 25. Del mismo modo, conocer al ser amado y formar un hogar en el cual encontrar la felicidad era un anhelo de muchos jóvenes de ambos sexos. Así mismo, los desengaños y frustraciones derivados de las relaciones amorosas eran más frecuentes entre estos.

La situación que mencionamos hasta aquí no era desconocida por los intelectuales de las elites que estudiaron los suicidios en la época. Desde esta perspectiva erudita y científica, los jóvenes, en especial de género femenino, eran vistos como más propensos a quitarse la vida, arrastrados por sus pasiones, en especial, el amor. En este sentido, los médicos alertaban sobre la perniciosa influencia de las obras literarias en el estado mental de la juventud. Los folletines de la época tenían tramas violentas, dramáticas e inmorales que despertaban las pasiones más intensas entre los adolescentes. El resultado, una poderosa sugestión que hacía crecer el número de los suicidios y los delitos. Al tratar este punto no faltaba la referencia al personaje creado por Johann Wolfgang von Goethe, el joven Werther. Éste se había convertido, desde la aparición de la novela escrita por Goethe (a fines del siglo XVIII), en un estereotipo de los suicidios por amor, dramáticos y novelescos, referencia a la que aludían los profesionales de la salud cuando hacían comentarios irónicos respecto de los suicidios por "amores contrariados", inspirados en las tramas de la literatura por entregas.

En trabajos anteriores, se han abordado los tipos narrativos y los principios morales que organizaban las narraciones de los suicidios en Buenos Aires durante el último tercio del siglo XIX. Así, fueron identificadas las explicaciones verosímiles elaboradas por el que se quitaba la vida y los integrantes de su red social; y, al mismo tiempo, los valores y creencias que daban sentido al acto suicida, es decir, los elementos del marco 
axiológico. En el presente trabajo, en cambio, hemos decidido poner el foco en las acciones comunicativas de estos suicidas apasionados.

\section{SUICIDIO Y ACCIÓN COMUNICATIVA}

En línea con los estudios sociales y culturales de la suicidiología, pensamos los suicidios como sucesos cargados de significado individual, aunque también colectivo. ${ }^{5}$ Es decir, son acciones que responden a las representaciones del sujeto como individuo y a la manera de representar a los que forman parte de su red social. Según Pierre Moron (1980), la autoagresión y la heteroagresividad (dirigida a un tercero) están conectadas. En este sentido, los suicidios y los significados que les otorgan los que se quitan la vida, en general, estarían relacionados con el vínculo con el prójimo. Según Moron, el motivo esencial es la reivindicación afectiva, es decir: "El sentido del deseo de autodestrucción es esencialmente hacer al prójimo responsable de la muerte: auto y heteroagresividad están indisolublemente ligadas" (Moron, 1980, p. 125).

Desde nuestra perspectiva, y a partir de lo estudiado en las fuentes, la intencionalidad puesta en el acto suicida implica otras posibilidades. Como expondremos a lo largo de este trabajo, además de la revancha o venganza, a través de la culpa, consciente o inconsciente, que el suicida busca generar en el otro significativo, las situaciones que hemos observado en la documentación analizada, desde una mirada cultural, son más variadas, así como las intenciones / motivos verosímiles manifestados.

Por esta razón, encontramos estimulante pensar las muertes por mano propia a partir de la teoría de la comunicación, en línea con lo que plantean autores como Birthe Loa Knizek y Heidi Hjelmeland (2011). Desde esta perspectiva, los suicidios son analizados como acciones comunicativas. Se parte de entender que todo lo que el ser humano hace transmite un mensaje a los demás individuos que forman parte de su contexto social, influyendo en ellos. En este sentido, al lastimarse, los que se agreden a sí mismos están comunicando algo a la red social que integran, o al colectivo. Desde este punto de vista, las muertes por mano propia son fenómenos duales: afectan al que se suicida y a los otros significativos a los que apela. Estos últimos reconstruyen luego de lo sucedido diálogos previos e interacciones. En cierta medida, la muerte por mano propia es ubicada como desenlace y encadenada con la serie de eventos previos.

Así, el que se agredía a sí mismo, en cierta medida, interpelaba al mundo en el que vivía y a los otros con los que interactuaba. A partir de esta perspectiva, consideramos los casos de muerte por mano propia a través de la comunicación que el individuo sin esperanzas intentaba establecer con su red social, y, dentro de esta, con los que identificaba como otros significativos. En este sentido, nuestro objetivo fue analizar las interacciones entre el suicida y el otro significativo al que apelaba con sus acciones. Como veremos, en muchos de los casos abordados para desarrollar este trabajo, la pareja (concubino/a, novio/a, amante, esposo/a) era el sujeto interpelado por los que se quitaban la vida; y, en menor medida, los padres del suicida o los de su amada/o, entre otros posibles interlocutores. En los relatos analizados, encontramos diversas interacciones con diferentes intenciones por parte del que se suicidaba. Había quienes manifestaban su dolor por percibir que era imposible establecer un vínculo amoroso con la persona deseada. Algunos de ellos expresaban su deseo de reencontrarse en el más allá con el ser amado. Otros, en cambio, se suicidaban con intenciones más agresivas: trataban de chantajear al sujeto objeto de deseo; y, en varios, la aniquilación de la propia vida era una forma de generar culpa, escándalo y sufrimiento en alguno o varios de los supervivientes.

\section{El SILENCIO DE los APASIONADOS}

A la hora de observar las acciones comunicativas mencionadas en estos relatos debemos destacar una primera actitud de los suicidas: el silencio y la reserva. Muchos de los que se quitaron la vida llevaron adelante acciones para mantener los detalles íntimos de su acto para ellos mismos y/o sus otros significativos. José Santiago Foa, 
inmigrante italiano, intentó quitarse la vida el 22 de enero de 1887. Para llevar adelante su acto suicida eligió una habitación del Hotel Génova. Allí, tomo una dosis de láudano. Fue rescatado a tiempo por el Dr. Manuel Blancas. Blancas le administró un antídoto que dejó a Foa fuera de peligro. Cuando fue interrogado por la policía, José se negó a revelar los detalles y los motivos que lo habían impulsado a tomar una determinación tan extrema. Sin embargo, de acuerdo con lo asentado en el sumario, la carta que fue encontrada en la habitación del hotel (no adjuntada al expediente) revelaba las circunstancias que Foa no quería dar a conocer. Según la policía, del contenido de la nota se deducía que fueron "amores contrariados" los que llevaron al suicida a intentar darse la muerte. ${ }^{6}$ Foa no tenía intenciones de manifestar en público sus frustraciones románticas; por otro lado, dejó una carta en la que expresaba las causas de su sufrimiento. Es probable, como sucede en otros casos, que la nota estuviera dirigida a uno de los deudos del suicida o a la propia persona que lo había rechazado; este último debe haber revelado el contenido del escrito a la policía. Lina Pirola (italiana, 38 años, viuda) también intentó envenenarse con láudano, sin embargo, no llegó a ser auxiliada a tiempo. Fue encontrada en la pieza de la casa de inquilinos que habitaba, ya sin vida, el 29 de octubre de 1886. Según algunos de los testigos que la conocían, en Europa ya se había querido suicidar por "amores contrariados" y sospechaban que esta fue la causa de su acto suicida. No fueron necesarios más detalles que esta explicación por parte de los testigos para dar cuenta del acto suicida de Lina; sin embargo, la suicida no buscó expresar o compartir sus sentimientos y los motivos de su aflicción con nadie más. Del mismo modo, luego del suicidio de Elena Cada, también fueron los miembros de su red social los que elaboraron el relato que asociaba su suicidio con sus desventuras amorosas. ${ }^{7}$ Para quitarse la vida, Cada recurrió a un medio más contundente que Pirola o Foa, pero sin atentar contra su rostro: se disparó con un revólver en el costado izquierdo de su cuerpo. Los hechos ocurrieron en la Confitería del “Gas”. Luego de recolectar los testimonios, el policía registró que la motivación de la autoagresión de Cada estaba vinculada con amores que habían sido frustrados. Al igual que Pirola, Cada no buscó que otros supieran las razones de su acto suicida, en este sentido, quizás prefirió llevarse a la tumba los detalles de lo sucedido, o, tal vez, su suicidio en sí contenía el mensaje tácito que buscaba transmitir a alguno/algunos de sus otros significativos.

En muchos de estos relatos, el suicida no había anunciado sus intenciones; tampoco había dejado una nota que explicara los motivos de sus actos a los miembros de su red social. Es decir, no había un mensaje explícito para las personas vinculadas al suicida. En varios, si sobrevivían, se negaban a declarar. Así, muchos suicidas eran cautelosos a la hora de revelar en público detalles acerca de sus pasiones y desgracias. Por ejemplo, Juan Castelleti (italiano, 30 años, marinero), sólo dejó una carta para el comisario, haciéndose responsable de su muerte. ${ }^{8}$ Se quitó la vida el 18 de agosto de 1879 . No dejó explicaciones de sus motivos, ni argumentos para justificar su acto suicida. Los testigos, por su parte, explicaron que Castelletti les había confesado que estaba enamorado de una joven a la que no podía olvidar. El diario "La Prensa" (20/08/1879), dio a conocer este caso y para explicar lo sucedido difundió lo declarado por Pedro Lameli, amigo del suicida. Según Lameli, Castelleti le había dicho que estaba "enamorado ardientemente". Estos detalles íntimos fueron revelados por terceros. Juan no dejó nada de esto asentado en su carta. Debemos tener presente que uno de los objetivos de los testigos era dar argumentos que alejaran toda sospecha de que se trataba de un homicidio. De este modo, los integrantes de la red vincular buscaban dar evidencia que fundamentara la verosimilitud del acto suicida como desenlace. Así, los detalles sobre las desdichas y los desengaños amorosos, en varios casos, fueron revelados por los sujetos que integraban la red social del que se quitó la vida. Así lo hicieron los que conocían a Héctor Semini (italiano, 21 años, un año de residencia, soltero, corredor de una casa introductora). De acuerdo con el sumario, este joven cortejaba a Luisa Gatti, para que accediera a casarse con él. ${ }^{9}$ Al momento de explicar el acto suicida de Héctor, los que declararon informaron que Gatti había declinado la propuesta de aquél y creían que éste era el suceso que lo había motivado a quitarse la vida (se disparó con un revólver en la sien derecha en la Plaza Vicente López). En otros episodios similares, tal vez, no existían mayores dudas sobre lo sucedido, es decir, no era necesario convencer al policía encargado del sumario de que se trataba de un suicidio. Así, no había motivos para declarar información acerca de la vida afectiva del difunto. En este 
sentido, cuando el suicida legaba una carta, en general, estaba dentro de un sobre cerrado, dejando claramente establecido quien era el destinatario de sus palabras finales; no tenía intenciones de que otros conocieran detalles sobre sus sentimientos.

En el caso de los hombres, suicidarse por tales motivos representaba una actitud vergonzosa, digna de permanecer en el misterio. Miguel Honoré (francés, 23 años, soltero, dependiente), intentó darse muerte el 13 de abril de 1884, a las 19:30hs, utilizando un revólver con el que disparó en dirección a su propio vientre. Honoré se negó a declarar a la policía los motivos de su desesperada determinación; sin embargo, el agente dejó sentado que era probable que la causa fuera algún "amor desgraciado". ${ }^{10}$ Miguel no quiso declarar los motivos de su pesar. Ángel Mascheroni (italiano, soltero, sin ocupación) tampoco demostró interés en comunicar a las autoridades los detalles del desengaño amoroso que lo había impulsado a quitarse la vida. ${ }^{11}$ El 25 de enero de 1883, Mascheroni ingirió pasta para matar ratones y cloroformo. Ángel era hermano de dos escultores. Estos declararon que Mascheroni sólo se ocupaba de la bebida, y no buscaba trabajo, desde que había sufrido un desengaño amoroso. Al principio, Ángel no quería declarar, pero, más tarde, manifestó que había tomado veneno porque había sido engañado por una mujer.

Estos suicidios de varones apasionados que se quitaban la vida por problemas amorosos eran los más cuestionados dentro del marco axiológico de las elites. Así lo resaltó el diario "La Nación”, el 31 de marzo de 1881, al informar sobre un acto suicida ocurrido el día anterior:

Los suicidios están tomando un notable incremento entre nosotros.

Parece que estos hechos lamentables tienden a propagarse de un modo alarmante, en vez de limitarse como fuera de desear. Jóvenes que apenas nacen a la vida, que tienen en perspectiva un porvenir risueño, que son necesarios a los suyos, se quitan la vida, las más de las veces por causas frívolas, acaso por los desdenes de una mujer coqueta, como si de una mujer se compusiera el mundo.

El suicidio, como recurso extremo de la desesperación, puede acaso disculparse, no justificarse, en una persona combatida por los sufrimientos, perseguida por la inclemencia, o acosada por la miseria; pero nunca en jóvenes inexpertos todavía por su corta edad, que no han tenido tiempo de sentirse impotentes para hacer frente a la adversidad.

En síntesis, desde la mirada del discurso científico y la perspectiva de las elites culturales, muchos de los suicidios eran la expresión de pasiones románticas exaltadas, que debían ser condenadas como frívolas y vergonzosas. Este romanticismo, que proponía exaltar los sentimientos de los hombres y mujeres sensibles, también era interpretado como uno de los responsables de que muchos, que ya estaban predispuestos al suicidio, terminaran llevando adelante esta extrema resolución por peleas o incidentes menores, o que se batieran a duelo para defender su honra, por medio de la violencia. El amor o el desengaño amoroso, además, podían arrastrar a las personas al vicio, la ambición desmedida y otras actitudes que no eran consideradas virtuosas. Por esta razón, aparecía la necesidad de una adecuada educación moral de los sentimientos que preparara a los futuros ciudadanos para enfrentar la vida y sirviera para prevenir la aparición de conductas desviadas, peligrosas y precoces.

En síntesis, no es extraño que una de las principales acciones comunicativas en los relatos vinculados con el amor, las pasiones y las relaciones de pareja fuera el silencio y la reserva por parte de los suicidas. Desde la perspectiva del marco axiológico de la época, quitarse la vida por estas "causas frívolas" era injustificado y vergonzoso. Al mismo tiempo, era una actitud verosímil, esperable, por parte de jóvenes románticos y mujeres sensibles.

\section{EXPRESAR EL SUFRIMIENTO}

Al consultar los sumarios judiciales, hemos encontrado indicios de algunas de estas representaciones estereotipadas que formaban parte de la cultura general y del sentido común acerca de los jóvenes y su sensibilidad. Este carácter novelesco aparece en el relato de las circunstancias del suicidio de Rodolfo Sepúlveda (peruano, 25 años). ${ }^{12}$ Este joven venía de Europa y se quitó la vida el 18 de noviembre de 1881, en 
los Bosques de Palermo, disparándose con un revólver en el corazón. De acuerdo con la narración elaborada por el policía que llevó adelante la investigación de su muerte violenta, la nota encontrada entre sus ropas tenía escrita una poesía romántica. Según lo publicado en los diarios "La Nación" y "La Prensa", el 20 de noviembre de 1881, en su último escrito, el suicida expresaba lo siguiente:

Lloré, no se porqué. Aun siento en mis mejillas ardientes huellas de un amargo llanto. Llore al ver desaparecer entre las ramas del sauce llorón, que cubrirá mi lecho mortuorio, los últimos rayos de sol. Llore al sentir pasar en el cercano paseo un carruage, el mismo que vi poco ha llevando a una niña hermosa como la juventud y a dos niñitas que se rieron de ver corretear por estas soledades a un caballero de galera de media vara; Llore al oír la alegre gritería de los muchachos bañándose en la playa de mas allá, llore en fin sin saber porque. Ahora ya no lloro, La noche esta cayendo. Todo esta tranquilo.... No ahí pasa otro carruage, lo oigo y sonrío... Los últimos reflejos del sol se pierden en las nubecillas del horizonte, lo veo y tranquilo admiro las variantes formas que les da el viento que carece de fuerza. ¿Si habrá tempestad? Para mi no!

No hemos encontrado una intención clara en el último escrito de este suicida. Al mismo tiempo, la nota tampoco tenía un destinatario específico. Sólo podemos identificar el estado de sensibilidad extrema del joven y la expresión de sufrimiento y confusión que nos transmiten sus últimas palabras. Según los cronistas, el joven Rodolfo provenía de una prestigiosa familia de Lima que había quedado en la ruina como consecuencia de la Guerra del Pacífico. Había sido enviado con cartas de recomendación para conseguir empleo en la ciudad. Quizás se sentía avergonzado por no lograr sus objetivos; tal vez, sentía que había defraudado a sus familiares; también es posible que sus recursos se estuvieran agotando. Sin embargo, su nota no incluye un pedido de perdón o una justificación de su acto suicida. Sólo nos transmite las intensas sensaciones y emociones, el dolor y el sufrimiento que el suicida experimentaba. De acuerdo con lo informado en el diario "La Prensa" (20/11/1881), la biblioteca del suicida contenía las siguientes obras, que daban cuenta del estado mental alterado del sujeto: "La princesa saltinbanqui", de Alexis Bonvier; "Guía de la conversación Español Francés"; "Rimas", de Gustavo A. Bécquer; "Marianela”, de Pérez Gáldos; "Memoramdum de medicina y cirujia"; "Le Bave de Paris", de Bongolez; y "Obras poéticas" de Espronceda. Los libros del suicida eran un indicio de su sensible e inestable carácter: la obra de Pérez Gáldos tenía como desenlace el suicidio de la protagonista; "La princesa saltinbanqui" era una novela dramática francesa de folletín; al mismo tiempo, Bécquer y Espronceda eran poetas románticos. Sepúlveda fue enterrado en el Cementerio de la Chacarita y en su tumba se colocó una cruz con su nombre, para que su familia pudiera encontrar el lugar donde descansaban sus restos, según lo relatado en el diario "La Nación" (20/11/1881).

Así, en algunos de los relatos, aunque no se conociera la causa, se presentaba a los protagonistas como jóvenes sensibles y románticos, al estilo "Werther". Manuel Martínez (auxiliar del inspector de telégrafos de la policía), el 29 de agosto de 1887, entró en la comisaría y pidió a uno de sus compañeros un libro de poesías y comenzó a leer la que tenía por título "El suicidio". Uno de los presentes interrumpió a Manuel y se ofreció a continuar leyendo. Otro de los policías que estaba allí escuchó a Martínez decir por lo bajo, "así se hace”, momentos antes de que se disparase con un revólver en la sien derecha. ${ }^{13}$ Es probable que Manuel estuviera tratando de comunicar a sus compañeros de trabajo el acto desesperado que estaba por cometer, fue un mensaje que no llegó a alertar al entorno a tiempo; las acciones comunicativas de Manuel fueron demasiado ambiguas para los receptores. El suicida no estaba culpando a sus vínculos, sus acciones tenían un fin más expresivo y orientado hacia los otros. Quizás estaba tratando de transmitir su sufrimiento y pedir auxilio de una forma indirecta; de seguro, la idea de comunicar directamente los sentimientos aflictivos a su entorno le provocaba incomodidad. Según el comisario y los otros policías nada parecía indicar que éste tomara la resolución de suicidarse, siempre había tenido un carácter jovial y agradable y se desempeñaba de forma responsable y comprometida en sus labores. Quizás imaginaban a un suicida como alguien melancólico y triste.

Como ya mencionamos, el mensaje del suicida, en algunos casos, no tenía un destinatario explícito. A veces, dedicaba la mayor parte de sus últimas palabras a expresar su sufrimiento, a exponer las causas de su determinación. Este tipo de acción comunicativa fue la que llevó adelante Paulo Piati, antes de intentar 
quitarse la vida. Cabe mencionar que la historia de Piati, así como el epitafio que dejó escrito en un papel, parecía extraída de una novela o folletín con desenlace trágico. Piati (italiano, 24 años, dos años de residencia en Argentina, soltero, tenedor de libros) intentó quitarse la vida al beber láudano en su habitación (vivía en una casa de inquilinos). ${ }^{14}$ Manifestó estar agobiado por todas sus desdichas, infamias y desengaños. De acuerdo con los testimonios recolectados por el policía, Paulo estaba enfermo de tisis (tuberculosis), no tenía recursos para cubrir sus necesidades básicas y había sido abandonado por su amor. A continuación, transcribimos el contenido de la nota suicida que dejó (traducido por la policía de la época):

\section{$1886-1888$}

Años infames y terribles

12 / Agosto

Hoy todo concluye para mí, tengo 24 años justos de edad y por ser mi cumple-años pienso concluir con esta vida infame y miserable inútil para mi y los demás, una vida llena de sinsabores y estupideces, he sufrido bastante desengaños, iras, he padecido sin cuento, estoy aburrido, cansado de todo y de todos. Muero. Quién sabe si en la muerte no encontraré algún alivio a mis males?

Escribo estas últimas líneas con el corazon despedazado, con el alma moribunda con mi imajinación convulsa por el último golpe sufrido.

No me quedaba más que el supremo placer del amor con un ser que me hacía feliz y al que adoraba con locura, bien también esto lo tengo, todos los caprichos.

Cuando te cansaras Oh Dios Poderoso de atormentar a esta tu criatura?

Según el mensaje que nos transmite en su carta, Paulo representaba el cariño de su amada como el único aliento para soportar los dolores que experimentaba. Para él, la vida era una sucesión de desencantos constantes (enojo, equivocaciones, desengaño, insatisfacción), que no ofrecía otra posibilidad más que disfrutar del amor (el "supremo placer") o morir. La fecha no era casual, el día de su cumpleaños parecía un buen momento para hacer un recuento de lo vivido. De acuerdo con el balance vital de los últimos años, ya no había más posibilidad de encontrar la felicidad, sólo sufrimiento; la balanza se inclinó hacia la muerte. La desesperación y el sentimiento de estar aislado de su red de vínculos eran completos: estaba "aburrido, cansado de todo y de todos" y, al mismo tiempo, sentía que su existencia "infame y miserable" era "inútil” para sí mismo y para sus otros significativos. En síntesis, las palabras finales de Piati no tienen un receptor explícito. Los enunciados de su nota suicida tampoco acusan o culpan de lo sucedido a personas directas. Por otro lado, tal vez, buscaba generar remordimiento en aquel amor que lo había abandonado. Sin embargo, esto no era mencionado de forma explícita; el eje del mensaje era manifestar el dolor que su situación presente le generaba.

\section{Preservar la memoria: el perdón y el último adiós...}

Mientras las acciones comunicativas de varios suicidas estaban orientadas a transmitir su sufrimiento a los integrantes de su red vincular, o a dar un justificativo a sus actos desesperados, otros trataban de preservar el cariño y un buen recuerdo en la memoria de sus otros significativos. Esta fue la intención que expresó Felipe Brust en la carta que dejó a su prometida, antes de suicidarse, el día de su boda. El 4 de junio de 1886, Felipe (oriental, 28 años, soltero, dependiente de una casa de comercio)se quitó la vida en la habitación que alquilaba. El dueño de la propiedad salió desesperado al escuchar la detonación del arma de fuego: Brust se había disparado con un revólver en la cabeza, mientras estaba sentado en una silla, y cayó al piso luego de perder el conocimiento. Allí fue encontrado por la policía. En una de las sillas del cuarto del suicida, encontraron la carta dirigida a su prometida, Catalina Cantoni. Encima de la misma había un papel que rezaba lo siguiente: "no quiero que nadie se entere de esta carta sino ella". Brust también dejó una carta para su hermano, Pedro. Tanto éste último como Catalina retiraron sus respectivas notas. Cantoni también pidió a la policía una foto suya que había quedado entre los papeles de Felipe, que la policía recolectó como parte del 
inventario. De lo relatado en el expediente podemos entrever que las cartas dejadas por Brust tenían un valor para sus destinatarios: tanto Catalina, su prometida, como su hermano recuperaron estos textos. Es probable que los mensajes de despedida, más allá de las desgraciadas circunstancias en las que fueron escritos, actuaban a modo de recuerdo del ser querido. Por otro lado, es posible que si la carta contenía alguna información íntima sobre los otros significativos y su relación con el suicida, éste y aquellos no tenían intención de compartirla con los policías o con los cronistas de la prensa. Cómo destacó Brust, sólo su prometida debía conocer sus últimas palabras, nadie más. ¿Cuál sería el contenido de la carta de Felipe a Catalina? De acuerdo con lo informado en el diario "La Prensa" (05/06/1886), en esta nota, Brust se despedía de ella tiernamente y le pedía perdón por el dolor que iba a causarle con su muerte. De este modo la nota, como acción comunicativa, estaba destinada a salvar el recuerdo del suicida entre los deudos. Según los cronistas, Brust estaba angustiado por contar con bajos ingresos. Estos no alcanzaban para darle a su prometida el estilo de vida que el deseaba brindarle. No era justificable que alguien en su sano juicio tomara la decisión de quitarse la vida en estas circunstancias, sin embargo, era verosímil imaginar la angustia que le generaba al "joven suicida" no poder proveer a su amada de una vida de abundancia y riqueza con sus precarios ingresos. Los relatos de este tipo dan cuenta de la presión que debieron haber sentido muchos jóvenes para poder cumplir con el horizonte de expectativas masculinas de la época. Por otra parte, también nos muestran acciones comunicativas que tenían por objetivo limpiar, al menos en parte, el recuerdo que el suicida legaba a su red de vínculos.

La nota dejada por Eduardo Chateau (francés, 40 años, soltero, desocupado) presentó una acción comunicativa similar. Chateau intentó suicidarse el $1^{\circ}$ de julio de 1884 en el hotel donde se alojaba (Hotel des Postes). Al principio, se negó a declarar las razones de su "extrema resolución”, pero el policía dedujo, por la carta que había dejado el suicida, que una mujer era la causa de sus pesares; en su nota, se despedía cariñosamente de ella. ${ }^{15}$

\footnotetext{
Amigos: No busquen [ilegible - ningún] papel, todos están en Europa desde [ilegible] solicito al Sr. Comisario que los 100 nacionales que estarán en mi bolsillo sean dados a mi [ilegible] amada 58 calle Cuyo, serán para [ilegible] mi [ilegible - duelo]. Muero porque no quiero o no puedo vivir más. Todas mis pertenencias del baúl para Camilo mi [ilegible] y el mejor de mis amigos.

Adiós a todos y a vos, mi dulce amiga, el mejor de los besos.

Perdón por todas las penas que te pude causar.

Adiós querida mía, adiós tesoro. Desde mi corazón, mil veces adiós.

Eduardo.
}

Esta nota fue incluida, traducida del francés al español, como parte de la noticia publicada al día siguiente de lo sucedido. De acuerdo con "La Nación" (02/07/1884), la joven que Eduardo amaba se llamaba Augusta, y trabajaba de niñera en la casa de José Pacheco. En esa misma residencia, había trabajado Chateau como mucamo y había conocido a Augusta. Chateau deseaba casarse con ella, pero, según el cronista, esto no fue posible debido a que los papeles necesarios para tramitar el enlace estaban en Europa y el novio no tenía dinero suficiente para traerlos. En síntesis: "Esta imposibilidad de llegar pronto a la realización de sus deseos y no otra causa ha sido la que ha impulsado a Chateau a atentar contra su vida". Al igual que en el caso de Felipe Brust, las pasiones nublaron el juicio del apasionado Chateau; éstas no le permitieron enfrentar los obstáculos para casarse con Augusta y ser feliz. Por otro lado, tanto Eduardo Chateau como Felipe Brust buscaron expresar su afecto y su sufrimiento, despedirse cariñosamente de las personas amadas y pedir perdón por el dolor que causarían con sus actos.

Melania Reymond de Gondrán también dejó un epitafio con un contenido similar. Melania sucumbió a su propia desesperación cuando empezó a imaginar que su compañero, Musiliar Lanci, la abandonaría. ${ }^{16}$ Melania había dejado a su marido, un hombre de apellido Gondran, que vivía en Francia, para seguir a su amado, Lanci. Éste era músico de profesión y vivía junto a su pareja y el hijo de Reymond. Éste tenía 6 años y había nacido de la unión de Melania y su ex marido. La familia de Reymond no aprobaba los "amores ilícitos" que tenía con Lanci, como los denominó la madre de Melania cuando fue llamada a declarar. Ésta última 
también destacó que su hija se había separado de su esposo con autorización de las autoridades eclesiásticas. El 22 de febrero de 1882, Reymond prendió el brasero de la pieza que habitaba con su familia, dejó el cuarto cerrado y murió asfixiada. Cuando Lanci declaró, entre sollozos y un dolor manifiesto, según lo relatado en el sumario, explicó que había pedido a Melania que le confesara ciertos detalles de su vida. Melania accedió y le contó lo que quería saber, pero quizás la reacción de su compañero la desestabilizó; Lanci sospechaba que Reymond se había suicidado por miedo a ser abandonada. ¿Qué secretos guardaba Melania? ¿Por qué pensaba que Lanci la dejaría librada a su suerte? ¿Algún episodio de infidelidad? Al parecer, el desgraciado artista se sentía arrepentido de su reacción y demostró estar lleno de tristeza por el trágico desenlace. Las dos cartas que dejó Melania, escritas detrás de una de las partituras de su compañero, tampoco nos brindan muchos indicios; éstas fueron publicadas en el diario "La Nación" (24/02/1882), días después de su muerte. Una de las notas dejadas contenía el siguiente mensaje:

Una hora antes de morir declaro que M Laug no tiene culpa alguna de mi suicidio y que siempre ha sido para mi un hombre bueno y honrado. Le suplico me perdone el sentimiento que le voy a hacer experimentar.

Perdon una y mil veces y si me has amado conservaras un piadoso recuerdo para esta Melania que te ha querido.

Melania Reymond. ${ }^{17}$

En la primera carta, la suicida confesó que era consciente del dolor que provocaría a su pareja y pidió perdón por ello, al mismo tiempo también solicitaba ser recordada con un sentimiento de compasión. Esta es la actitud que Melania buscó despertar en los destinatarios de sus dos notas. La otra, dirigida a la madre de la suicida, daba alguna otra información sobre lo sucedido:

Querida Madre: Te recomiendo a mi pobre hijo, con quien, si yohubiera sido ua buena madre, debiera vivir para protegerlo y formarlo un hombre.

Sabes que voy por el camino de la desgracia; hoy, vencida por los remordimientos, con la deshonra en perspectiva, que es mas grande que todo, pues que el que se llama mi esposo va a abandonarme y no veo para mi mas camino que la muerte.

Tu me perdonaras y a el tambien porque yo sola soy la unica culpable - solamente yo.

Adiós, mi querida madre; perdona a esta hija que te ha dado no solo todos los disgustos, sino también toda la deshonra. Un ultimo adios, madre; vuélveme a perdonar, y, sobre todo, te recomiendo a mi hijo.

Melania Reymond.

Melania pedía, entre otras cosas, perdón a su madre por toda la deshonra, ella era la única responsable de todo lo sucedido. Sin embargo, no explicitaba qué clase de acciones la habían llevado a comprometer su honor, el de su pareja y el de su familia. En las noticias publicadas en el diario "La Prensa" y "La Nación" se explicitaba que trataban la información sobre el caso con suma discreción: "Las causas del suicidio son de carácter tan intimo que no ha creído conveniente la familia autorizar su publicidad" ("La Prensa", 23/02/1882). El cronista de "La Nación" (23/02/1882) acotaba: "Hay en las causas que han motivado este suicidio hechos de importancia y de verdadero interés, que omitimos por pertenecer a la vida íntima de aquella desgraciada”. Tal vez, Melania confesó a su pareja alguna clase de infidelidad que comprometía la honra de éste y, por esta razón, quizás, Lanci mostró intenciones de terminar la relación entre ambos. Más allá de las circunstancias delicadas implicadas en el suicidio de Melania, lo que nos interesa destacar son las acciones comunicativas que llevó adelante por medio de sus cartas. En primer lugar, tomar plena responsabilidad por su acto suicida. Aunque, por otro lado, de forma implícita, había una acusación a su pareja por abandonarla; tal vez, en parte, Melania deseaba generar ese dolor en su compañero. Al mismo tiempo, estos textos buscaban conseguir el perdón de sus otros significativos por sus faltas; es decir, su intención era enmendar, de alguna forma, las consecuencias de sus acciones deshonrosas pasadas. De forma explícita, Melania solicitaba ser preservada en la memoria de los deudos. Tal vez, también imaginaba el relato de su vida que sería narrado a su hijo luego de su muerte, el cual encomendaba a su madre con sus últimas palabras.

Como veremos a continuación, otros mensajes tenían fines más agresivos. En algunos casos, la carta buscaba despertar la culpa en el receptor. Era un ajuste de cuentas, una última palabra que dejaba establecidos a la víctima y al victimario. Un medio para transmitir el resentimiento del suicida al que culpaba de su dolor. 


\section{ReSENTIMIENTOS MÁs ALLÁ DE LA MUERTE...}

La última nota de Felipe Pedro Martínez (oriental, 18 años, soltero, tipógrafo) fue dirigida a la mujer que lo había desilusionado. Martínez intentó quitarse la vida el 19 de noviembre de 1878, alrededor de las 23:15 hs. ${ }^{18}$ La policía intentó averiguar las razones que habían llevado a Felipe a cortarse la garganta, el pecho y el vientre. Descubrieron que su acto suicida estaba relacionado con la falta de medios materiales para casarse y formar un hogar. Según los testigos, Martínez estaba enamorado de una joven y le pidió que lo esperara y le fuera fiel, mientras ahorraría los recursos necesarios para concertar el matrimonio. Sin embargo, su amor se desligó del compromiso. Le envió una carta en la que se desdecía de la palabra que le había dado, alegando problemas de familia. En su nota suicida, Felipe le reclamaba por esta traición a su confianza:

Aquel que al hacer una promesa debe saber: que bien o mal, debe cumplirla; obtenga o no lo que esperaba.

No debe retractarse de ella aunque vea delante sí, la negra muerte; no solo para él, sino para alguien más. M.F.P.

Martínez utilizo las últimas palabras para remarcar las faltas del otro significativo a las que estaban dirigidas. En este caso encontramos un intento de sembrar la culpa y el remordimiento en los deudos.

Una actitud similar manifestó Ovidio Canesse en la nota que redactó antes de quitarse la vida. En algunos relatos, encontramos que los padres de alguno de los miembros de la pareja se oponían al matrimonio de estos o a que continuaran con su relación. La narración de los sucesos que culminaron con el suicidio de Ovidio Canesse sigue este tipo de trama y tiene el mismo desenlace trágico y violento que la historia de Felipe Pedro Martínez: apareció colgado de un tirante de su habitación (en un conventillo), el 2 de octubre de 1887. ${ }^{19}$ Ovidio (italiano, 21 años, soltero, marinero), estaba prometido a una joven llamada Ida. Sin embargo, como declararon los testigos (entre los que se contaba el padre de su novia), la madre de Ida se oponía a este matrimonio. Así, se sospechaba que este fuera el móvil del acto suicida del joven Canesse. Según el diario "La Nación" (03/10/1887) fue "inducido al suicidio por unos amores contrariados". La noticia de lo sucedido también fue publicada por "La Prensa" (03/10/1887), con el habitual titular: "Amores contrariados". El escritor de la nota traía a colación otro intento de suicidio reciente, el de la novia de Canesse, Ida Gambedotti. Días atrás, Ida había intentado envenenarse al tomar una disolución de fósforos; la causa: amores contrariados por sus tutores. Según la versión de los hechos informada por el diario, dentro de la caja de cigarros que se encontraba en el baúl de Ovidio Canesse había cartas, en su mayor parte escritas por Ida, y otra del suicida, dirigida al comisario, en la que le manifestaba que "a nadie se culpara de su muerte, pues el se había suicidado porque la señorita Ida Gambedotti no lo quería ya”. Además de lo mencionado en la noticia, Ovidio dejó varias cartas que fueron adjuntadas al sumario judicial levantado con motivo de su muerte. Una de éstas, estaba dirigida a la madre de Ida, la "Despreciada Señora" Luigina. Entre otras cosas, Canesse culpaba a esta "vil mujer" de todo lo que sucedía y de su suicidio. Le recordaba que, aunque él ya no estuviera vivo, Dios continuaba presente y le preguntaba, de forma retórica, quién llevaba más honor en la cara, ella, "una aristocrática", o un "mísero marinero". Al mismo tiempo, le expresaba que la perdonaba y la odiaba "hasta más allá de la tumba”. La razón de su resentimiento: había acusado a Ida de ser una puta, cuando ella era un ángel. También le señalaba que, si él hubiera querido, habría podido hacerla suya. Finalmente, se despedía: "Adiós oh vil mujer. La odio por siempre. El difunto, Invidio Canese". ${ }^{20}$ Las últimas palabras de Canesse estaban cargadas de una profunda aversión hacia la madre de su amada. Al mismo tiempo que le dedicaba todo su desprecio y defendía la honra de su ángel, Ida, Ovidio exaltaba su virilidad, el habría podido seducir a esta joven angelical de haberlo deseado. Como podemos apreciar al leer la carta, las acciones comunicativas de Canesse eran agresivas, buscaba generar un sentimiento de culpa en Luigina, y, al mismo tiempo, exponerla ante todos como la responsable del acto suicida de Ida y del suyo. La intención del suicida era expresar el odio en público para poner en evidencia y denunciar hechos que consideraba injustos. Por otra parte, es probable que el suicida esperara generar cierta empatía por su situación a nivel colectivo. Los sinceros sentimientos 
de amor manifestados por los jóvenes tenían un valor legítimo, aunque se rechazaran el accionar desmedido de algunos sujetos, por ejemplo, los que llegaban a poner fin a sus vidas por conflictos amorosos. En este sentido, como menciona Carlos Mayo (2004), durante el transcurso del siglo XIX, y sobre todo a partir de la influencia del romanticismo, el amor ganó legitimidad como valor y como fundamento de las relaciones de pareja, y, en paralelo, los criterios coloniales, que anteponían la conveniencia, el poder patriarcal, el linaje y la pureza de sangre, como condiciones para elegir esposo/a, perdieron peso. Así, el hecho de que los jóvenes que se amaban buscaran la forma de estar juntos no dejaba de resultar heroico y su amor un sentimiento noble.

Por esta razón, el doble suicidio de los enamorados despertaba sentimientos ambiguos: por un lado, se rechazaba el violento y triste final extremo trágico y violento; por el otro, muchos se horrorizaban y conmovían, al mismo tiempo, al ver en lo sucedido los nobles sentimientos de amor propios de la juventud y los dramas románticos. Solamente encontramos un expediente con una historia de este tipo, el que relata los suicidios de Victorino Belmonte y Malvina Mernes. ${ }^{21}$ Belmonte, jornalero argentino de 21 años, se había enamorado de Malvina, una joven empleada doméstica de 18 años. Según las declaraciones relevadas por la policía, Mernes huyó del domicilio donde realizaba sus tareas en compañía de Belmonte. Ambos habían acordado quitarse la vida ingiriendo arsénico. Así lo hicieron en un café de la ciudad. De acuerdo con el testimonio que llegó a dar Victorino, luego de fugarse, Malvina le reveló que quería suicidarse. En un gesto de romanticismo apasionado, Belmonte le propuso terminar su existencia juntos. Las últimas palabras de Victorino, contenidas en una de las notas que encontró la policía, fueron las siguientes:

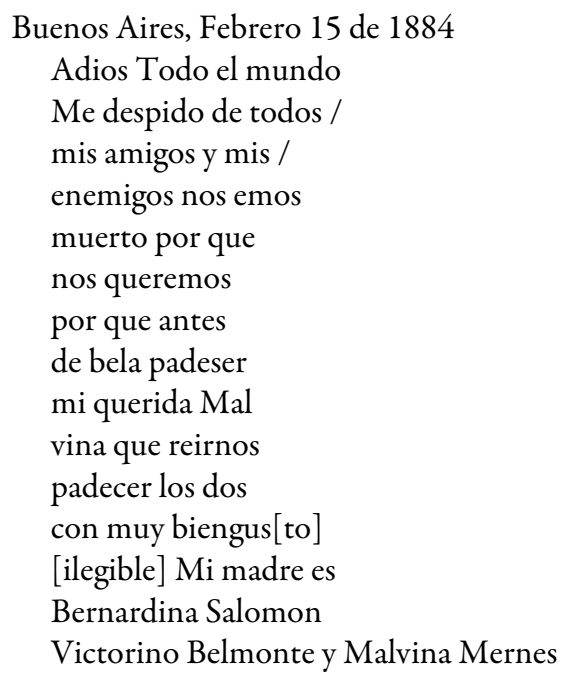

Sin mencionarlos, la nota de Victorino y Malvina ponía en evidencia a sus enemigos y las acciones que estos últimos llevaron adelante para separarlos. En este sentido, había una intención de apelar a la simpatía que generaban este tipo de relatos, la lucha de los jóvenes enamorados por defender sus genuinos sentimientos.

En el caso de Laureana Peralta (argentina, entre 22 y 25 años, viuda), el otro significativo al que buscó hacer responsable de sus actos suicidas fue su pareja, Agustín Olivera. Olivera sospechaba de la fidelidad de Laureana y, por esta razón, había abandonado a su compañera en más de una oportunidad. Peralta llevó adelante varios actos suicidas. La primera vez, el 10 de abril de 1881, Laureana intentó quitarse la vida al tomar una disolución de fósforos en agua. Luego de hacerlo, se arrepintió y mandó llamar a su familia. En la misma casa vivían Adelina Leiva (prima de Laureana) y los miembros del matrimonio Cairo, Dolores y José. Estos explicaron que, ese día, Laureana fue a llevar una carta a Olivera; al volver, manifestó deseos de acostarse y se retiró a su habitación. Al entrar allí, Dolores encontró a Laureana recostada, largando espuma por la boca; cerca, en el suelo, estaba la taza quebrada con los fósforos esparcidos a su alrededor. De acuerdo con las declaraciones de los testigos, los motivos detrás de este incidente eran las peleas entre Olivera y Laureana. ${ }^{22}$ Peralta escribió tres cartas antes de intoxicarse. Una estaba dirigida a Adelina. A través de esta nota, le comunicaba sus intenciones 
de envenenarse "para dejar de sufrir". Al mismo tiempo, le pedía que buscara a Agustín y le entregara en mano un mensaje dirigido a éste (tal vez cambió de opinión y decidió enviar la carta ella misma, como mencionaron los testigos). Asimismo, Laureana le pedía a su prima, en nombre de las cenizas de la madre de Adelina, que diera aviso a su padre de lo sucedido. Por último, le pedía perdón y le deseaba a su pariente toda la felicidad. La segunda nota suicida era más breve. Estaba dirigida a José y Dolores; además de explicar que se suicidaba para dejar de sufrir, les pedía que, en cuanto la encontraran, llamaran a Agustín y le dieran a conocer lo sucedido. La carta destinada a Agustín Olivera también fue incluida en el expediente. Por la riqueza de este documento, lo transcribimos a continuación:

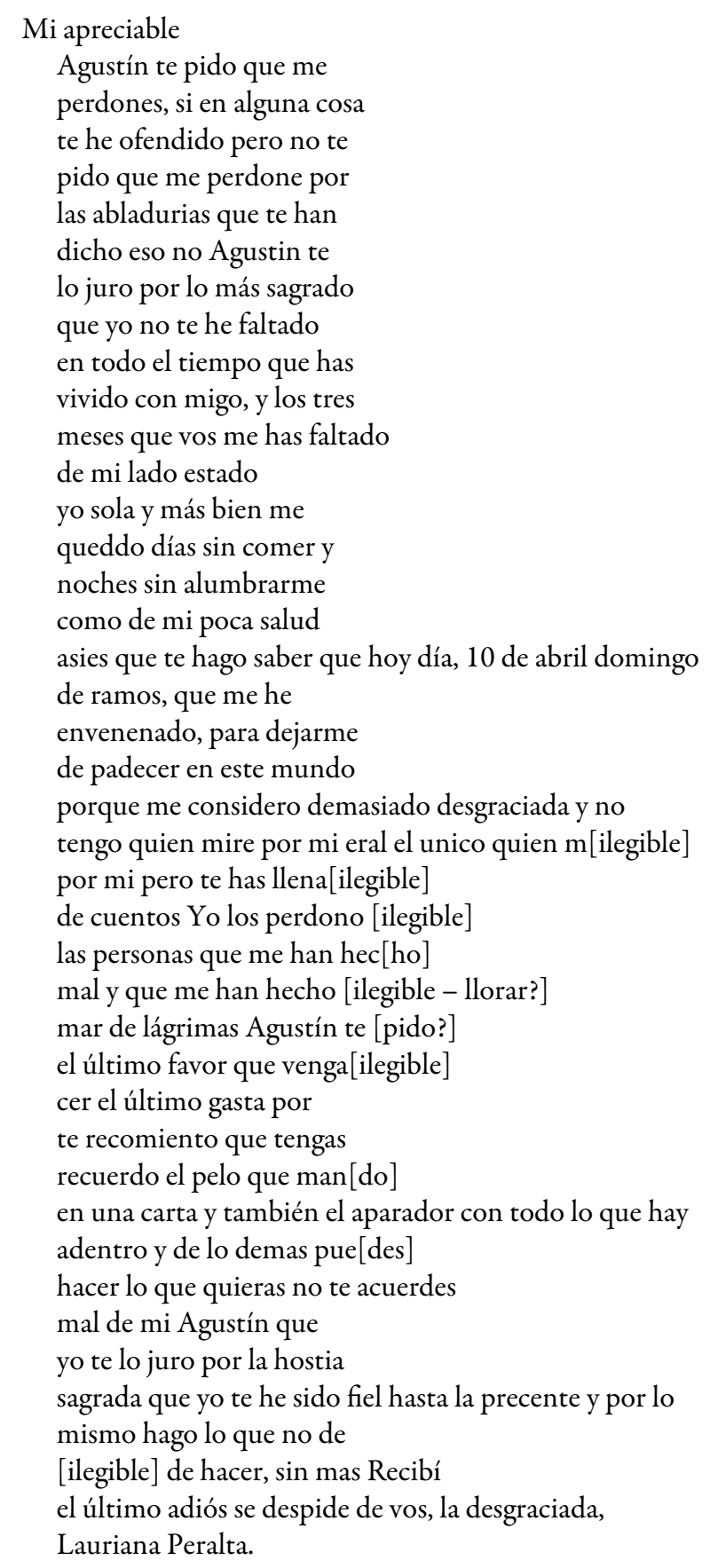

Por lo que Laureana relata en esta nota, su compañero la acusaba injustamente de serle infiel, por esta razón, estaban separados desde hacía tres meses. Ella, por su parte, le juraba a Agustín lo contrario, "por la hostia sagrada”. Asimismo, pedía perdón si lo había ofendido, pero no se disculparía por chismes y rumores 
falsos. En su mensaje, además de darle el último adiós, también le pedía que no la olvidara, que conservara sus cabellos en un sobre. Laureana se posicionaba como la víctima del relato, la "desgraciada", abandonada por su pareja, había padecido hambre y frío por su ausencia, mientras ella había permanecido siempre a su lado.

La segunda vez que encontramos noticias de Laureana Peralta fue en un expediente que relata sucesos ocurridos el 18 de marzo de $1882^{23}$. A pesar de los celos y sentimientos posesivos, la relación de Peralta y Olivera continuó y, en algún momento, ambos volvieron a vivir juntos; sin embargo, habían vuelto a separarse y Laureana vivía en otra casa de inquilinos. Allí bebió una disolución de fósforos en kerosén. En esta oportunidad, fue descubierta por Juana Salvadores, una amiga, a la que estaba dirigida una de las cartas que dejó la suicida. En ésta le expresaba sus últimas disposiciones:

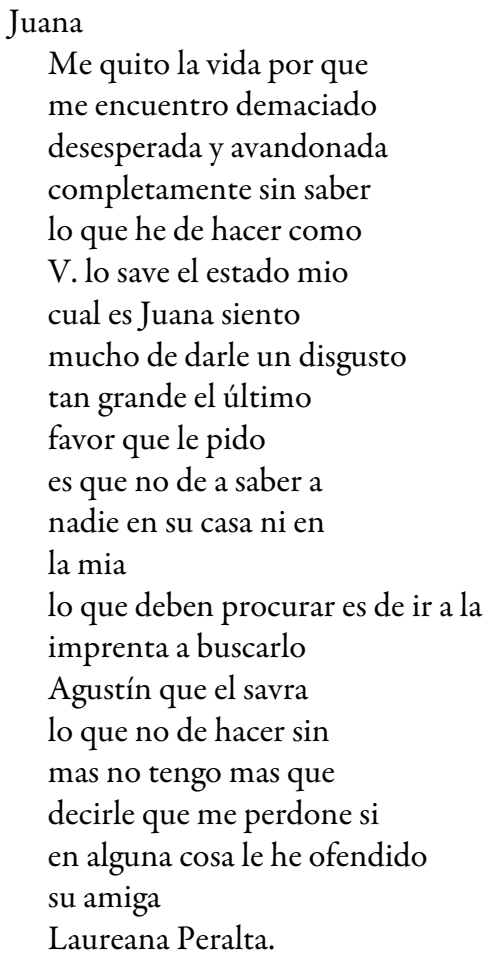

En las páginas del sumario, también encontramos una nota dirigida a Agustín Olivera. En dicho escrito, nuevamente podemos identificar el intento de Peralta por generar culpa y remordimiento en su ex-pareja: "hoy 18 de marzo de 1882 es el último día de mi vida causa tulla y de mi quirido compadre Carranza". Frente a los rumores maliciosos y falsos, la joven suicida respondía: "Agustín yo muero con mi conciencia lipia por que creo de no averte ofendido a vos de ningun modo por que si es respeto a la gran calunia que me ha levantado mi compadre no lo es cierto y lo apruebo con mi vida". No sabemos con certeza la relación de Laureana con Carranza o el vínculo de parentesco que los unía, pero a éste también lo responsabilizaba de su muerte, aunque manifestaba que le daba su perdón. Al mismo tiempo, Peralta pedía a su ex-pareja que le hiciera una serie de favores. En primer lugar, que no diera a conocer lo sucedido a su familia (eran muy "ingratos" con ella). En segundo lugar, solicitaba que avisara a su madrina para que se hiciera cargo de sus restos. También le pedía a Olivera que pagara sus deudas ("te pido de favor que le pagues a Juana docientos pesos para que pague su relo[reloj] que lo empeño para darme a mi para que me mudara y también le pagaras a lopes catorce pesos que le pedí emprestado"). Por último, le solicitaba que le diera el último adiós el día de su entierro. Como en el relato de lo sucedido el año anterior, en las peleas entre Olivera y Peralta había de por medio sospechas de infidelidad. Al parecer, estos rumores habían vuelto a llegar a oídos de Agustín. De nuevo, la narración de lo sucedido, contada desde la perspectiva de la suicida, la posicionaba como la víctima: acusada injustamente, abandonada por su compañero, con necesidades materiales y deudas a las que no podía responder. Al mismo tiempo, queda explícito el deseo de generar culpa en Olivera por lo sucedido y 
por los términos de la separación. En este sentido, en la nota suicida también figuraba lo siguiente: “Agustín hasta donde ha llegado tu ingratitu de haber permitido que yo me quite la vida antes de pagarme una triste y micerable pieza sin mas me despido de vos para siempre y te deceo toda la felicidad". Al parecer, Agustín tal vez se negó a dar socorro a su ex-pareja y no dio relevancia a las amenazas que ésta última le expresó. Esta carta quizás era parte de la venganza final de Laureana: generar remordimiento y culpa en aquél que la había abandonado, cuando la leyera. Tal vez, sólo era parte de un acto suicida que tenía como fin, consciente o inconsciente, retener a Olivera. A diferencia de otros relatos, la carta quedó en el expediente. Agustín no consideraba importante o valioso este documento, quizás tampoco creía que su honra o su reputación estuvieran en duda. En este sentido, la madre de Olivera declaró que Laureana debía estar padeciendo de la manía del suicidio, ya que este era el tercer intento que la joven llevaba adelante. ¿Qué credibilidad podía tener una persona con sus facultades mentales alteradas?

Al observar las cartas que Laureana Peralta dejó para su pareja, encontramos junto a las acciones comunicativas regulativas agresivas (los intentos de sembrar culpa y remordimiento en los otros significativos) enunciados con palabras que denotan la preocupación del suicida por el recuerdo que legaba a sus deudos. Así, junto a las acciones comunicativas regulativas agresivas encontramos también acciones regulativas oblativas que tenían por objetivo preservar la memoria y el recuerdo del suicida entre los integrantes de su red vincular.

\section{CONSIDERACIONES Finales}

En este trabajo, nos propusimos analizar los relatos de suicidios vinculados con el amor, como eje temático. Asimismo, incluimos también aquellas historias que presentaban datos sobre las interacciones entre los miembros de la pareja. En este sentido, nos parecía central rescatar la relación del suicida con la persona amada, como otro significativo. Cabe destacar que la mayoría de los suicidas en estas historias dramáticas y novelescas eran adolescentes y adultos jóvenes. Esto no resultaba sorpresivo para los contemporáneos; los médicos alertaban sobre los peligros de ese romanticismo mortal, que promovía las pasiones desenfrenadas. Los más jóvenes y las mujeres eran los más propensos a dejarse arrastrar por estos sentimientos exaltados, en especial, el amor. Era muy verosímil imaginar a sujetos con estas características de sexo y edad quitándose la vida por este tipo de "causas determinantes": era esperable que fueran más proclives a caer en la desesperación por influencia de dilemas amorosos o sentimientos asociados, como los celos; o estar envueltos en combates relacionados con asuntos del corazón. En síntesis, había un preconcepto sobre el carácter de los jóvenes, imaginados como individuos sensibles y apasionados, como el Werther de Goethe, que se refleja en las declaraciones de los testigos y en los informes de la policía.

A partir de las historias de estos héroes y heroínas románticos, este trabajo estuvo orientado a analizar las interacciones entre los que se quitaban la vida y sus parejas, como otros significativos. Al indagar estas tramas con final dramático, nos encontramos con algunas actitudes y acciones que se reiteraban. En primer lugar, como en muchos otros suicidios, no sólo los de este eje temático, identificamos la determinación de guardar silencio y no revelar lo que estaba sucediendo o lo que el suicida sentía. Si dejaban cartas, estas eran dirigidas a miembros de la red de vínculos más cercanos en sobre cerrado. En algunos, el mensaje se resumía en un último adiós, un pedido de perdón o una expresión del dolor y la desesperación por percibir que era imposible establecer un vínculo amoroso con la persona deseada. En ciertas ocasiones, el destinatario de la misma era el ser amado, y, a veces, también odiado con la misma intensidad. En este sentido, encontramos actos suicidas e interacciones que tenían objetivos más agresivos. Así, por ejemplo, vimos, de forma reiterada, expedientes que relatan tentativas de envenenamiento o de autolesión que fueron ensayadas delante de la pareja o el individuo deseado. A veces, el mensaje estaba dirigido a alguno de los padres o tutores que se oponía a la relación amorosa de sus hijos. En algunos casos, parecía haber una intención de chantaje. Es decir, el objetivo de forzar al entorno a ceder a los deseos del suicida; por ejemplo, en el caso del sujeto que estaba por 
ser abandonado, retener a su amado. En varios otros, la aniquilación de la propia vida era una forma de generar escándalo, dolor y culpa en alguno o varios de los supervivientes. El objetivo de estos actos suicidas iba más allá de lo expresivo o lo afectivo, eran suicidios con la intención de sembrar remordimiento en otros. Por otra parte, si bien existían este tipo de acciones comunicativas regulativas agresivas, también encontramos muchos suicidas preocupados por el recuerdo que dejaban de ellos a sus deudos. En algunos casos ambas acciones se entremezclaban. Así, junto a las palabras que buscaban generar dolor y pesar también eran incluidas otras que estaban orientadas a preservar la memoria del suicida entre los otros significativos.

\section{Bibliografía}

Arroyo, J. (2018a). El silencio de los desesperados: representaciones de los suicidios en Buenos Aires (1860-1888). En C. Barile y C. Castiglione (comps.), Morir no es poco. Estudios sobre la muerte y los cementerios (pp.71-88). Buenos Aires: Ediciones Continente.

Arroyo, J. (2018b). Los significados de la desesperación. Las representaciones del suicidio en Buenos Aires (1868-1903) (Tesis doctoral inédita). Universidad Nacional de La Plata, Facultad de Humanidades y Ciencias de la Educación, La Plata, Argentina.

Arroyo, J. (2020). Desespero e paixões sem freio. As Representações do suicídio e o significado do amor em Buenos Aires durante o último terceiro do século XIX. Revista Latino-Americana de História (en prensa). Url: http:// projeto.unisinos.br/rla/index.php

Bjerg, M. (2017). Emociones, Inmigración y Familia en la Argentina del siglo XIX. Anuario IEHS, 32, 7-26.

Bjerg, M. (2019). Lazos rotos: la inmigración, el matrimonio y las emociones en la Argentina entre los siglos XIX y XX. Bernal: Universidad Nacional de Quilmes.

Caminotti, D. (2010). Morir en el territorio de Neuquén: una aproximación al estudio del suicidio (1903-1957). En G. Rafart (comp.), Historia social y politica del delito en Patagonia. Neuquén: Educo.

Fitzpatrick, S. (2011). Looking Beyond the Qualitative and Quantitative Divide: Narrative, Ethics and Representation in Suicidology. Suicidology Online, 2, 29-37.

Gayol, S. (2004). Sociabilidades violentas o el imposible amor popular. En H. Biagini y A. Roig (dir.), El pensamiento alternativo en la Argentina del siglo XX. Tomo I (pp. 219-232). Buenos Aires: Biblos.

González, J. (2019). El suicidio como problema público en Argentina (Tesis de maestría inédita). Universidad Nacional de Lanús, Maestría en Epidemiología, Gestión y Políticas de Salud, Lanús, Argentina.

Guy, D. (2014). Prostitución y suicidio en Buenos Aires, 1880-1900. En D. Barrancos, D. Guy y A. Valobra (eds.), Moralidades y comportamientos sexuales: Argentina, 1880-2011. Ciudad Autónoma de Buenos Aires: Biblos.

Hjelmeland, H. (2010). Cultural Research in Suicidology: Challenges and Opportunities. Suicidology Online, 1, 34-52.

Lefebvre, H. (2006). La presencia y la ausencia. Contribución a la teoría de las representaciones. México: FCE.

Lobato, M. (2011). Te amo, te odio, te quiero: una aproximación a la cultura afectiva de las clases populares en el Río de La Plata, 1880-1930. En G. Chicote y B. Göbel (eds.), Ideas viajeras y sus objetos: El intercambio entre Alemania y América Austral (pp. 339-349). Madrid: Bibliotheca Ibero-Americana.

Mayo, C. (2004). Porque la quiero tanto. Historia del amor en la sociedad rioplatense (1750-1860). Buenos Aires: Biblos. Moron, P. (1980). El suicídio. Buenos Aires: Editorial Ábaco.

Otero, M. (1991). El suicidio en la ciudad de Buenos Aires: su nacimiento como problema social(Tesis de licenciatura). Universidad de Buenos Aires, Facultad de Filosofía y Letras, Buenos Aires, Argentina.

Owens, C., Owen, G., Belam, J., et al. (2012). Suicide communication events: Lay interpretation of the communication of suicidal ideation and intent. Social Science \& Medicine, 75, 419-428. 


\section{ReFERENCIAS HEMEROGRÁFICAS}

Conato de suicidio. (31/03/1881). La Nación.

¿Suicidio o duelo?. (19/11/1881). La Nación.

Era suicidio. (20/11/1881). La Nación.

Suicidio.(23/02/1882). La Nación.

Novedades policiales. (24/02/1882). La Nación.

Tentativa de suicidio. (02/07/1884). La Nación.

Suicidios. (03/10/1887). La Nación.

Suicidio. (20/08/1879). La Prensa.

El suicida. (20/11/1881). La Prensa.

Suicidio de una señora. (23/02/1882). La Prensa.

Joven suicida. (05/06/1886). La Prensa.

Amores Contrariados. (03/10/1887). La Prensa.

\section{Notas}

1 Hemos encontrado pocas investigaciones que aporten a la comprensión del suicidio desde una perspectiva histórica en Argentina, por ejemplo: Otero (1991, 2004), Caminotti (2010), Guy (2014), Arroyo (2018a y b) y González (2019).

2 Este trabajo retoma parte de las ideas y datos presentados en el noveno capítulo de la Tesis Doctoral del autor. Agradezco al Consejo Nacional de Investigaciones Científicas y Técnicas (CONICET), por brindarme el financiamiento necesario para llevar adelante mis estudios de postgrado y, en la actualidad, por proveer los fondos para seguir con mi investigación en la etapa postdoctoral. Asimismo, quiero dar mi agradecimiento mi directora, la Dra. Andrea Reguera, a mi Codirectora, Silvia Mallo, y a los jurados que evaluaron la tesis, la Dra. Sandra Gayol, el Dr. Gustavo Vallejo y el Dr. Pablo Cowen, por sus valiosos aportes, comentarios y sugerencias. También quiero agradecer de forma especial a los equipos de trabajo de las siguientes instituciones, que atendieron mis consultas y facilitaron el acceso a la documentación existente: Departamento de Documentos Escritos del Archivo General de la Nación, Hemeroteca “José Hernández" (Legislatura de la Ciudad Autónoma de Buenos Aires), Biblioteca Nacional "Mariano Moreno”, Biblioteca Prebisch (Banco Central de la República Argentina).

3 Parte de este material fue consultado por Donna Guy (2014), para estudiar los casos de suicidio de las prostitutas de la ciudad de Buenos Aires, entre 1880 y 1900.

4 Para llevar adelante este trabajo, de los 724 casos de suicidio encontrados en el AGN, FTC, hemos analizado 84 narraciones cuyas causas determinantes estuvieron asociadas con el amor y los conflictos de pareja: por ejemplo, "desengaño amoroso", "celos", "amores contrariados", etc., así como aquellos “dramas de amor" o "crímenes pasionales", según la prensa, los suicidios dobles y las tentativas de homicidio o agresiones físicas seguidas del acto suicida del asesino / agresor. Para un análisis de los conflictos conyugales de la población inmigrante que arribó al Río de la Plata, en las décadas finales del siglo XIX, puede mencionarse, entre otros, los trabajos de María Bjerg $(2017,2019)$. Sobre la cultura afectiva de las clases trabajadoras, durante este período, véase también: Lobato (2011).

5 Véase, entre otros, Hjelmeland (2010), Fitzpatrick (2011) y Owens et al. (2012). El concepto de representación utilizado en nuestra investigación fue elaborado a partir de las ideas expuestas por Henri Lefebvre (2006).

6 AGN, FTC-SE, Legajo F21, Foa, José Santiago, sumario sobre la tentativa de suicidio de éste.

7 AGN, FTC-SE, Legajo C12, Cada, Elena, por tentativa de suicidio.

8 AGN, FTC-SE, Legajo B40, C16, Castelletti, Juan, s/suicidio.

9 AGN, FTC-SE, Legajo S46, Semini, Héctor, s/suicidio.

10 AGN, FTC-SE, Legajo H7, Honoré, Miguel, s/tentativa de suicidio.

11 AGN, FTC-SE, Legajo M25, Mascheroni, Ángel, s/tentativa de suicidio [Cartas - dos].

12 AGN, FTC-SE, Legajo S21, Sepúlveda, Rodolfo por su suicidio.

13 AGN, FTC-SE, Legajo M39, Martínez, Manuel, su suicidio.

14 AGN, FTC-SE, Legajo P40, Piati, Paulo, por tentativa de suicidio.

15 AGN, FTC-SE, Legajo C28, Chateau, Eduardo, s/tentativa de suicidio.

16 AGN, FTC-SE, Legajo R21, Reymond de Gondran, Melania, por suicidio. 
17 La traducción de las cartas publicadas en el diario "La Nación” es fiel al contenido de las notas adjuntadas en el expediente que contiene el sumario.

18 AGN, FTC-SE, Legajo M15, Martínez, Felipe Pedro, Tentativa de suicidio.

19 AGN, FTC-SE, Legajo C38, Canesse, Ovidio, s/suicidio.

20 En otra de las cartas, Cannese se despedía de uno de sus tíos, de apellido Passerini. Allí le solicitaba que depositara dinero suyo (17.500 liras) en donde ya le había indicado con anterioridad. También le explicaba que para no vivir en deshonor era necesaria su muerte, lamentando los hechos que evitaron que pudiera "vivir feliz junto al objeto que amo más que a mí mismo".

21 AGN, FTC-SE, Legajo B23, Belmonte, Victorino y Mernes, Malvina s/suicidios.

22 AGN, FTC-SE, Legajo P22, Peralta, Laureana, s/suicidio.

23 AGN, FTC-SE, Legajo P23, Peralta, Laureana, por tentativa de suicidio.

\section{BY-NC-SA}

